\title{
Expression of cyclin DIa and DIb as predictive factors for treatment response in colorectal cancer
}

\author{
MP Myklebust', Z Li ${ }^{2}$, TH Tran ${ }^{2}$, H Rui $^{2}$, ES Knudsen ${ }^{2}$, H Elsaleh ${ }^{3}, \varnothing$ Fluge $^{4}$, B Vonen $^{5}$, HE Myrvold $^{6}$, S Leh $^{7}$, \\ KM Tveit ${ }^{8}$, RG Pestell ${ }^{2}$ and $O$ Dahl $^{*, 1,4}$ \\ IInstitute of Medicine, Section of Oncology, University of Bergen, Bergen 502I, Nonway; ${ }^{2}$ Department of Cancer Biology, Kimmel Cancer Center, Thomas \\ Jefferson University, Philadelphia, PA, USA; ${ }^{3}$ Academic Unit of Internal Medicine, The Australian National University Medical School, The Australian \\ National University, Canberra ACT 0200, Australia; ${ }^{4}$ Department of Oncology and Medical Physics, Haukeland University Hospital, Bergen 502I, \\ Norway; ${ }^{5}$ Department of Gastrointestinal Surgery, University Hospital of North Nonway, Tromsø, Nonway; ${ }^{6}$ Department of Gastrointestinal Surgery, \\ St Olavs Hospital, Trondheim University Hospital, Trondheim, Nonway; ' Department of Pathology, Haukeland University Hospital, Bergen 502 I, Norway; \\ ${ }^{8}$ Department of Oncology, Oslo University Hospital and University of Oslo, Oslo, Norway
}

BACKGROUND: The aim of this study was to investigate the value of the cyclin DI isoforms DIa and DIb as prognostic factors and their relevance as predictors of response to adjuvant chemotherapy with 5-fluorouracil and levamisole (5-FU/LEV) in colorectal cancer $(\mathrm{CRC})$.

METHODS: Protein expression of nuclear cyclin D Ia and D I b was assessed by immunohistochemistry in 335 CRC patients treated with surgery alone or with adjuvant therapy using 5-FU/LEV. The prognostic and predictive value of these two molecular markers and clinicopathological factors were evaluated statistically in univariate and multivariate survival analyses.

RESULTS: Neither cyclin DIa nor DIb showed any prognostic value in CRC or colon cancer patients. However, high cyclin DIa predicted benefit from adjuvant therapy measured in 5-year relapse-free survival (RFS) and CRC-specific survival (CSS) compared to surgery alone in colon cancer $(P=0.012$ and $P=0.038$, respectively) and especially in colon cancer stage III patients $(P=0.005$ and $P=0.019$, respectively) in univariate analyses. An interaction between treatment group and cyclin DIa could be shown for RFS $(P=0.004)$ and CSS $(P=0.025)$ in multivariate analysis.

CONCLUSION: Our study identifies high cyclin D la protein expression as a positive predictive factor for the benefit of adjuvant 5-FU/ LEV treatment in colon cancer, particularly in stage III colon cancer.

British Journal of Cancer (2012) I 07, |684-|69|. doi:I0.1038/bjc.2012.463 www.bjcancer.com

Published online 25 October 2012

(C) 2012 Cancer Research UK

Keywords: cyclin DIa; cyclin DIb; colorectal cancer; treatment response; $1 \mathrm{HC}$

Colorectal cancer (CRC) is one of the most common malignancies worldwide, with an incidence of more than 660000 new cases annually (Ferlay et al, 2010). The most clinically used prognostic factor for this cancer type is tumour stage at the time of diagnosis. At this time, no prognostic or predictive molecular markers are considered standard in the selection of proper treatment for each patient. Standard treatment differs, but the present treatment strategies for colon cancer include surgery, with adjuvant chemotherapy for patients with locally advanced cancer. Rectal cancer is mainly treated by surgery, including radiotherapy, with or without chemotherapy as a sensitiser, prior to surgery to maximise the treatment effect in advanced stages. Rectal cancer patients generally do not receive adjuvant chemotherapy in Norway. Some patients do not respond to the chemotherapy given, and some could have been cured by surgery alone. Markers for better prediction of response and benefit from adjuvant chemotherapy in CRC would clearly improve both patient care and health-care resource utilisation.

*Correspondence: Dr O Dahl; E-mail: olav.dah|@helse-bergen.no Received 2 July 2012; revised 5 September 2012; accepted 19 September 2012; published online 25 October 2012
Cyclin D is an important regulator of the cell cycle that drives progression through $G_{1}$ in response to mitogenic signals (Sherr, 1995). Type D cyclins form holoenzymes together with cyclindependent kinases (cdks) 4 and 6. Phosphorylation of pRb by cyclin $\mathrm{D}$ facilitates the expression of cyclin $\mathrm{E}$, a positive regulator of the $G_{1}$ checkpoint (Lukas et al, 1995; Ohtsubo et al, 1995; Vidal and Koff, 2000). In mammalian cells, there are three homologous D-type cyclins: D1, D2 and D3. Among these, cyclin D1 is most commonly expressed in several human cancers (Diehl, 2002). In colon cancer, overexpression of nuclear cyclin D1 has been shown to have a pivotal role in tumorigenesis and cellular metastases (Arber et al, 1996; McKay et al, 2000a; Mermelshtein et al, 2005). In colon cancer cell lines, cyclin D1 antisense reduced cellular growth (Arber et al, 1997) and cyclin D1-deficiency conveyed resistance to tumour formation induced by APC mutation in transgenic mice (Hulit et al, 2004). The human cyclin D1 gene is situated on chromosome 11q13 and has five exons (Inaba et al, 1992; Betticher et al, 1995). A polymorphism, A870G, located at the splice donor region at the exon-intron 4 boundary produces two distinct mRNA transcripts named isoforms a and b. The G870 allele results in the cyclin D1a transcript, which is the welldescribed form. An alternative splice product, cyclin D1b, arises 
from the A870 allele, which hinders splicing and allows for read-through into intron 4 and a premature termination of transcription (Betticher et al, 1995; Holley et al, 2001; Howe and Lynas, 2001). Thus, isoform b, which is the alternatively spliced transcript, encodes a truncated protein where the C-terminus of cyclin D1 is replaced by a shorter sequence from intron 4 . However, individuals homozygous for G/G can still produce cyclin D1b transcript (Bala and Peltomaki, 2001; Holley et al, 2001). The half-lives of the two isoforms have been shown to be the same in model systems, but cyclin D1b was strictly nuclear (Lu et al, 2003; Solomon et al, 2003). The mentioned studies suggest that cyclin D1b may be a stronger oncogene, as its capability to transform cells was increased compared to cyclin D1a. Both isoforms can stimulate cdk4/6 activity, but cyclin D1b has reduced ability to phosphorylate pRb (Solomon et al, 2003). Cyclin D1b has been linked to increased cancer risk in some studies (Kong et al, 2001; Wang et al, 2002, 2003; Le Marchand et al, 2003;), but the evidence is not consistent (Cortessis et al, 2003; Schernhammer et al, 2006). In addition to its cdk-binding function, D-type cyclins have additional cdk-independent properties in cellular growth, metabolism and cellular differentiation (Fu et al, 2004).

DNA repair proteins have been identified as interaction partners of cyclin D1 (Li et al, 2010; Jirawatnotai et al, 2011). It has been shown that cyclin D1a, but not cyclin D1b, recruitment to chromatin is sufficient for DNA damage response (DDR) to be initiated (Li et al, 2010). Findings from the same study indicated that the knockdown of endogenous cyclin D1 in colon cancer cells reduced the DDR in response to 5-FU treatment. We therefore hypothesised that treatment response to 5-FU in CRC, especially the stage III colon cancer patients, could be associated with the level of cyclin D1 protein, in particular cyclin D1a, in tumour cells from these patients.

\section{PATIENTS AND METHODS}

\section{Study population}

Among 425 enrolled patients, a total of 412 patients diagnosed with operable CRC were found to meet the inclusion criteria in a prospective and randomised clinical study from January 1993 to October 1996 (Dahl et al, 2009). The detailed patient characteristics and inclusion criteria have been presented elsewhere (Dahl et al, 2009). In brief, to be included, histologically diagnosed radical resection for primary adenocarcinoma in rectum or colon and regional lymph nodes had to be confirmed. The mean number of lymph nodes examined was 8.7, a number that reflects the level of practice at the time in Scandinavia (Derwinger et al, 2007; Edler et al, 2007). Distant metastases were excluded and evaluated by chest $\mathrm{X}$-ray, ultrasound or computed tomography of the abdomen, in addition to blood tests including serum CEA. Age limits were set to 18-75 years. In addition, patients were required to not have other diseases that could interfere with the administration of systemic chemotherapy or prior cytotoxic therapy. All patients included were classified as stage II or III according to the TNM classification. The patients were randomly allocated to treatment with surgery alone $(N=206)$ or surgery with adjuvant chemotherapy $(N=206)$. None of the rectal cancer patients had preoperative radiotherapy.

The study was approved by the regional ethics committee, the Norwegian Medicines Control Authority, and the Data Inspectorate. All patients gave their written, informed consent before randomisation.

\section{Chemotherapy and follow-up}

Treatment with 5-FU started with a loading course within 42 days from the date of surgery, giving $450 \mathrm{mg} \mathrm{m}^{-2}$ intravenously (i.v.) daily for 5 days and levamisole $50 \mathrm{mg}$ orally $\times 3$ for the first 3 days.
Maintenance therapy started 3 weeks later with weekly i.v. 5-FU $450 \mathrm{mg} \mathrm{m}^{-2}$, combined with levamisole per os $50 \mathrm{mg} \times 3$ for 3 days every second week. The maintenance therapy lasted for a total of 48 weeks. The patients were carefully followed up by the authors throughout the time period of the study and until 5 years. Standard follow-up forms were prospectively collected and submitted to the study centre. Follow-ups were scheduled every 6 months with clinical examination including chest X-ray, ultrasound of the abdomen, blood count and s-CEA, and rectoscopy for rectal cancer patients. Ultrasound was used as the screening method, and positive findings were confirmed by CT or MR. Colonoscopy was included every 3 years. Complete follow-up was available for all patients included. The protocol for detection of relapses was uniform throughout the patient group over the time of follow-up. Cancer-specific mortality was defined as death from CRC in patients with confirmed diagnosis. Autopsy was performed when the cause of death was uncertain.

\section{Tissue microarray (TMA) and immunohistochemistry (IHC)}

Tissue microarray was constructed from formalin-fixed and paraffin embedded archival tissue samples from 409 of the eligible 412 patients included in the study. Cores of $1.0 \mathrm{~mm}$ were punched from representative areas of the primary tumours, from macroscopically normal colon or rectal mucosa, and from lymph nodes with synchronous metastases and mounted in recipient paraffin blocks using a Manual Tissue Arrayer MTA-1 (Beecher Instruments Inc., Sun Prairie, WI, USA). For each patient included in the TMA, the number of samples present in the array varied from one to three representative samples from each tumour.

Immunohistochemistry and AQUA analyses were performed as previously described (Mercier et al, 2009). The primary antibodies used were anti-cytokeratin (AE1/AE3, Dako, Carpinteria, CA, USA) and anti-cyclin D1a (clone SP4, Lab Vision, Freemont, CA, USA); the cyclin D1b antibody specificity has been described (Wang et al, 2008). Briefly, after deparaffinisation and rehydration of array sections, antigen retrieval was performed by microwave treatment in citrate buffer (pH 6, Dako). Sections were blocked with $10 \%$ goat serum and followed by incubation of primary antibodies to cyclin D1a or cyclin D1b at a dilution of 1:50 for $1 \mathrm{~h}$. Sections were then washed thrice with TBS and subsequently incubated with mouse anti-cytokeratin antibody for $1 \mathrm{~h}$. The cyclin D1a and cyclin D1b antibodies were detected using an anti-rabbit horseradish peroxidise-conjugated secondary antibody (EnVision + , Dako), followed by incubation with tyramide-Cy5 (Perkin-Elmer, Waltham, MA, USA). Cytokeratin was visualised by further incubating the sections with an anti-mouse secondary antibody conjugated to Alexa 488 (Molecular Probes, Eugene, OR, USA). Finally, all sections were stained with $4^{\prime}$,6-diamidino-2-phenylindole (DAPI, Vector Laboratories, Burlingame, CA, USA) for nuclear visualisation. Automated quantitative analysis was performed using the AQUA/PM2000 Imaging Platform (HistoRx, Branford, CT, USA) as described (Dolled-Filhart et al, 2006). Tissue array slides were scanned and images of each tissue were captured at different channels, detecting Alexa 488, Cy5, or DAPI. AQUA software was then used to identify epithelial masks based on Alexa 488-positive cytokeratin-expressing cells. DAPI signal was used to identify nuclei. The cytoplasmic region was determined by subtracting the nuclear region (DAPI) from the tumour mask (cytokeratin). AQUA scores for cyclin D1a and cyclin D1b represent average signal intensities within epithelial cells.

Based on the median staining intensity within each cell compartment, the cyclin D1 isoforms were classified as 'low' or 'high'.

\section{Statistical analysis}

The associations between survival and staining of each of the two isoforms of cyclin D1 were estimated using the Kaplan-Meier 
method, and the log-rank test was used to compare survival between groups. A Cox regression hazards model was used for the estimation of the hazard ratio in multivariate analyses, where tumour stage, treatment group, localisation of tumour, histological grade, cyclin D1 staining and interaction variables were included. Relapse-free survival was calculated from the date of randomisation to the date of clinically confirmed relapse in months or the last date of follow-up. For the calculation of CSS, death from CRC was recorded; all other causes of death were handled as censored. CRC-specific survival was calculated from the date of randomisation to the date of death caused by CRC or the last date of followup. Representativity of the successfully stained groups for the whole patient series was checked by $t$-test and chi-square goodness-of-fit analyses. All statistical testing was performed using PASW 18 Statistics (SPSS Inc., Chicago, IL, USA). In twosided tests, $P<0.05$ was considered statistically significant.

\section{RESULTS}

\section{Patient characteristics and IHC}

Of 412 patients included in this study, 335 patients were successfully stained and included in the analyses of cyclin D1 isoforms (Figure 1). Of these, 111 experienced relapse and 97 died of colon cancer. We experienced a significant loss of samples during staining and scoring. By statistical analyses, the samples successfully stained for cyclinD1 isoforms were found to be representative of the whole cohort of 412 patients included in the initial study (Supplementary Table 4).

For cyclin D1a, the total number of patients with tumours that were successfully stained and evaluated was 293 . Of these, 83 died from CRC and 96 presented with relapse. The median value for nuclear cyclin D1a was 23.4, with 146 patients in the 'low' group and 147 in the 'high' group. There were 324 patients with successful cyclin D1b staining of tumour tissue. In this group, the
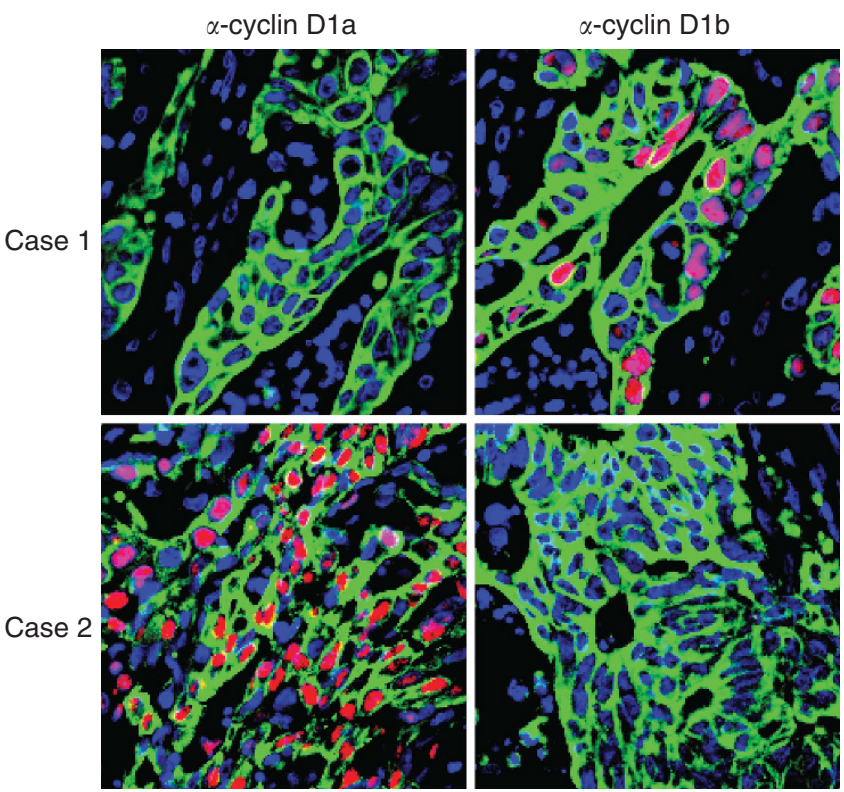

Figure I Immunohistochemistry for cyclin DIa and cyclin DIb using isoform-specific antibodies. The cyclin Dla antibody used was clone SP4 (Lab Vision), and the cyclin DIb antibody specificity has been described (Wang et al, 2008). Representative examples of colon cancer samples are shown. Case I expresses nuclear cyclin DIb. Case 2 expresses nuclear cyclin Dla.

Table I Patient characteristics for patients successfully stained for cyclin DIa

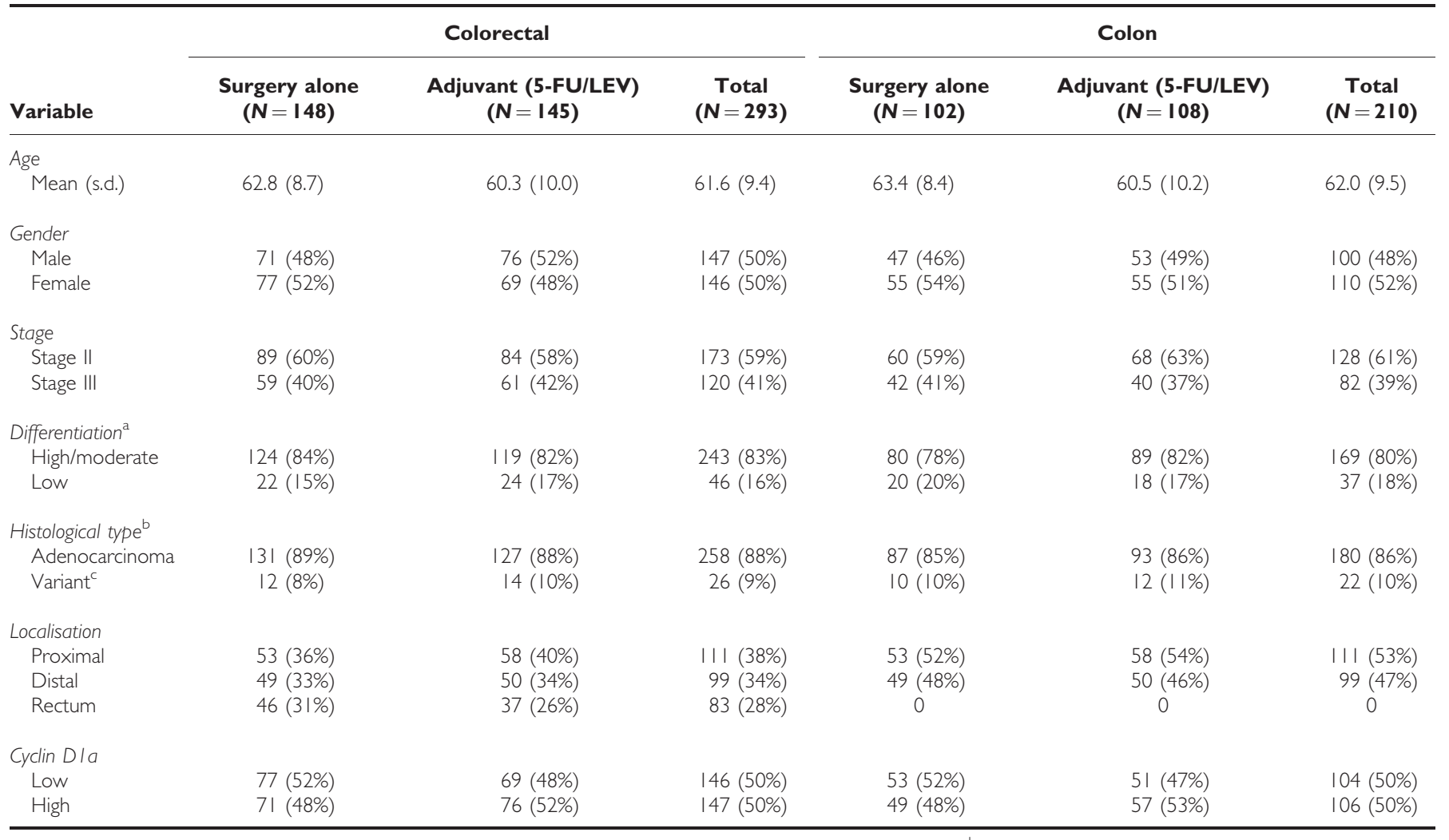

Abbreviation: 5-FU/LEV = 5-fluorouracil and levamisole. ${ }^{\mathrm{a} D a t a}$ regarding differentiation were missing for four patients. ${ }^{\mathrm{b}}$ For histological type, accurate data were missing for nine patients. 'Variant includes mucinous and signet-ring carcinoma. 
number of events was 96 deaths from CRC and 110 relapses. For cyclin D1b, the median value for the nuclear staining of the tumours was 45.8 , with 162 patients in both the 'low' and 'high' group. The characteristics for patients included in the analyses of nuclear cyclin D1a protein expression are shown in Table 1, and in Supplementary Table 2 for cyclin D1b. Patients in the two

Table 2 Multivariate analyses of characteristics associated with RFS and CSS in colon cancer tumours stage II and III successfully stained for cyclin DIa

\begin{tabular}{|c|c|c|c|c|c|c|}
\hline \multicolumn{7}{|l|}{ Stage } \\
\hline Stage III vs II & 4.621 & $2.717-7.862$ & $<0.001$ & 2.789 & $1.406-5.533$ & 0.003 \\
\hline \multicolumn{7}{|l|}{ Tumour localisation } \\
\hline Distal colon vs proximal colon & 1.468 & $0.894-2.408$ & NS & 1.194 & $0.7 \mid 1-2.004$ & NS \\
\hline Poor vs high/moderate diff. & 1.436 & $0.790-2.612$ & NS & 1.224 & $0.648-2.312$ & NS \\
\hline \multicolumn{7}{|l|}{ Treatment group } \\
\hline Adjuvant vs surgery alone & 1.454 & $0.750-2.819$ & NS & 1.327 & $0.675-2.609$ & NS \\
\hline \multicolumn{7}{|l|}{ Cyclin D I a status } \\
\hline High vs low & 1.649 & $0.822-3.307$ & NS & 0.322 & $0.085-1.221$ & 0.096 \\
\hline \multicolumn{7}{|l|}{ Interaction } \\
\hline \multicolumn{7}{|l|}{ Interaction } \\
\hline Stage* ${ }^{*}$ clin D la status ${ }^{\mathrm{a}}$ & - & - & - & 6.634 & $1.621-27.143$ & 0.008 \\
\hline
\end{tabular}

Abbreviations: $\mathrm{Cl}=$ confidence interval; $\mathrm{HR}=$ hazard ratio; $\mathrm{NS}=$ not statistically significant. ${ }^{a}$ The interaction variable stage* ${ }^{*}$ cyclinD I a was not significant and thus not included in the model for RFS.
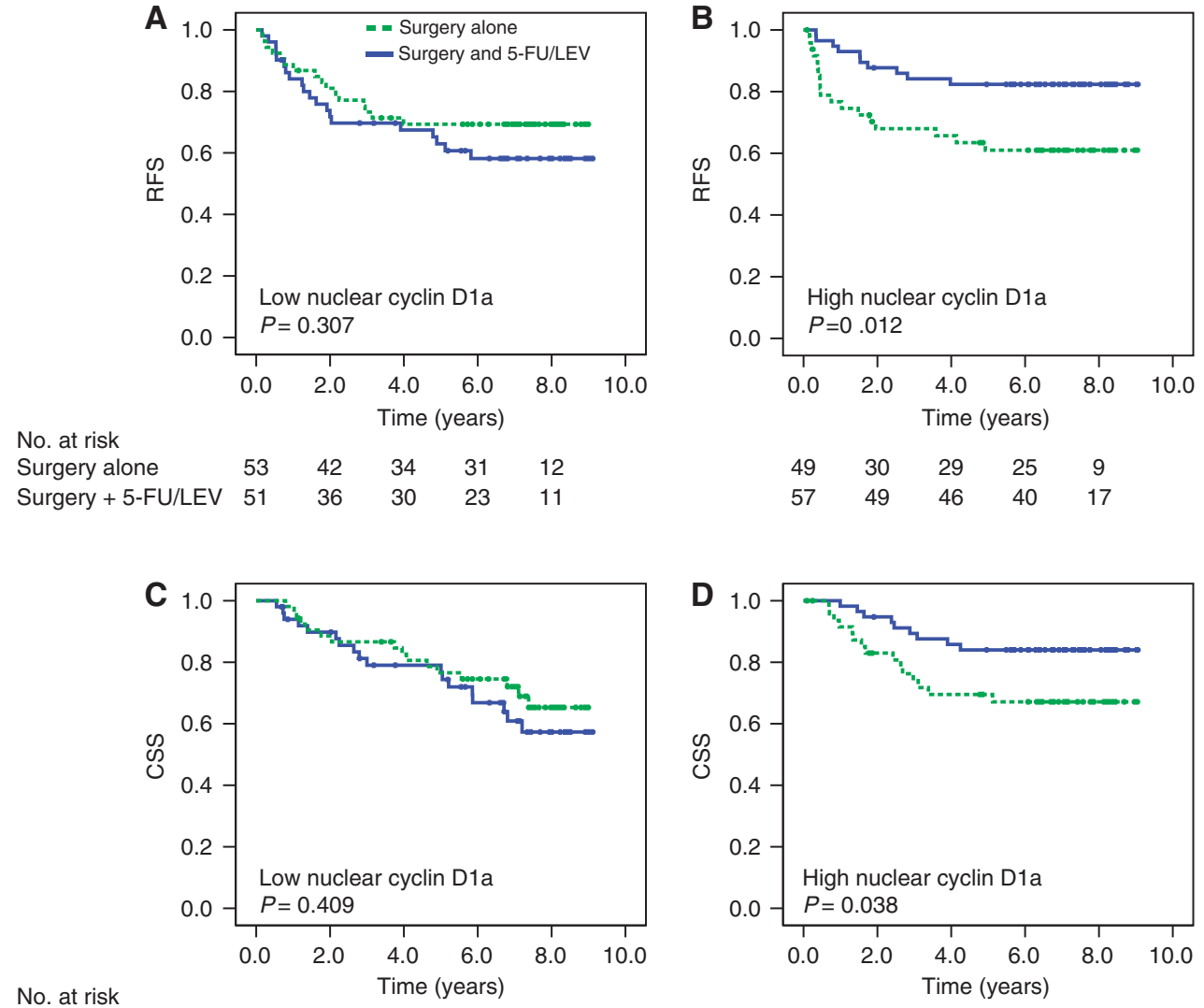

No. at risk

Time (years)

$\begin{array}{llllll}\text { Surgery alone } & 53 & 46 & 41 & 34 & 12\end{array}$

$\begin{array}{llllll}\text { Surgery + 5-FU/LEV } & 51 & 43 & 34 & 26 & 11\end{array}$

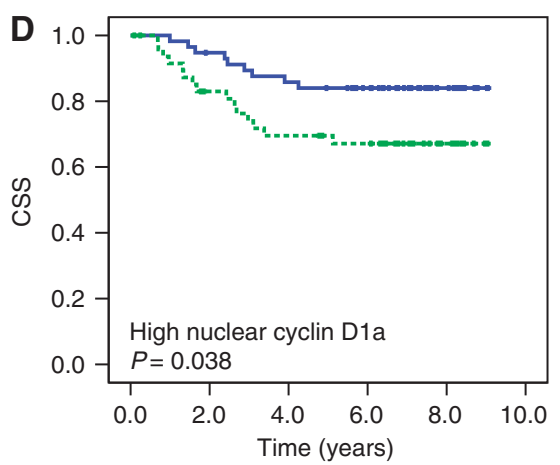

$\begin{array}{lllll}49 & 37 & 31 & 28 & 11\end{array}$

Figure 2 Colon cancer stage II and III patients and treatment response according to nuclear cyclin D Ia expression. The curves generated by the KaplanMeier method with P-values from the log-rank test show treatment response measured by RFS $(\mathbf{A}$ and $\mathbf{B})$ and CSS $(\mathbf{C}$ and $\mathbf{D})$ in patients with low nuclear cyclin DIa (A and $\mathbf{C}$ ) and high nuclear cyclin DIa (B and D). Blue represents patients treated with surgery plus adjuvant therapy (5-FU/LEV), green represents those treated with surgery alone. Abbreviations: CSS = cancer-specific survival; RFS = relapse-free survival. 
treatment groups were well balanced with respect to gender, age, stage (II and III), tumour site in colon, and cyclin D1a and D1b status. Associations between cyclin D1a and D1b and other clinicopathological variables are shown in Supplementary Table 1 and 3, respectively.

Stage is expected to have a prognostic value in colon cancer. This was indeed true in our colon patients successfully stained for both cyclin D1a and D1b, with significantly poorer prognosis of the stage III patients compared to stage II in univariate analyses. The 5-year RFS for stage II vs stage III was $82 \%$ vs $43 \%$, respectively $(P<0.001)$. For CSS, the results were similar, $90 \%$ vs $53 \%$, respectively, for stage II compared to stage III $(P<0.001)$. Multivariate analyses confirmed stage to be an independent predictor of survival in this cohort (Table 2).

\section{Prognostic value of cyclin D1a and D1b}

To evaluate the prognostic value of nuclear cyclin D1a and D1b, we analysed survival in the group of patients that had been randomised to surgery alone. No significant prognostic value for low or high nuclear cyclin D1a could be demonstrated for either RFS or CSS for CRC $(P=0.333$ and $P=0.381)$, colon cancer $(P=0.317$ and $P=0.688)$, or colon stage II $(P=0.654$ and $P=0.512)$ or III $(P=0.104$ and $P=0.317)$. Similar results were obtained for the prognostic value of cyclin D1b for RFS and CSS in CRC $(P=0.419$ and $P=0.552)$, colon cancer $(P=0.391$ and
$P=0.508)$ and colon cancer stage II $(P=0.593$ and $P=0.735)$ and III $(P=0.531$ and $P=0.817)$.

\section{Predictive value of cyclin D1a and D1b}

The predictive value of nuclear cyclin D1a and D1b for adjuvant treatment with 5-FU/LEV was evaluated by comparing RFS and CSS in patients treated by surgery alone or by adjuvant therapy with 5-FU/LEV in groups of patients defined by low or high cyclin D1a or cyclin D1b. A predictive value for nuclear cyclin D1a was demonstrated for colon cancer, as patients with high expression of this protein showed longer 5-year RFS and 5-year CSS when treated with 5-FU/LEV, compared to surgery only (Figure 2). The Kaplan-Meier analyses showed that 5-year RFS for patients with low nuclear cyclin D1a treated with surgery only vs adjuvant therapy (5-FU/LEV) was $69 \%$ vs $63 \%(P=0.307)$. For CSS, the 5 -year rate for both treatment groups in these patients with low cyclin D1a expression was $77 \%(P=0.409)$. In the 'high' group, the 5 -year RFS was $61 \%$ vs $82 \%$ for patients treated with surgery alone or with adjuvant therapy, respectively $(P=0.012)$. There was also a statistically significant difference in this 'high' group for 5-year CSS $(67 \%$ vs $84 \%, P=0.038)$. No such difference in treatment response could be demonstrated for the rectal cancer patients or the total cohort of colorectal patients (results not shown). When we divided the colon cancer patients into groups defined by stage, no predictive value of cylinD1a could be demonstrated for stage II colon cancer patients. Stage III patients with high cyclin D1a
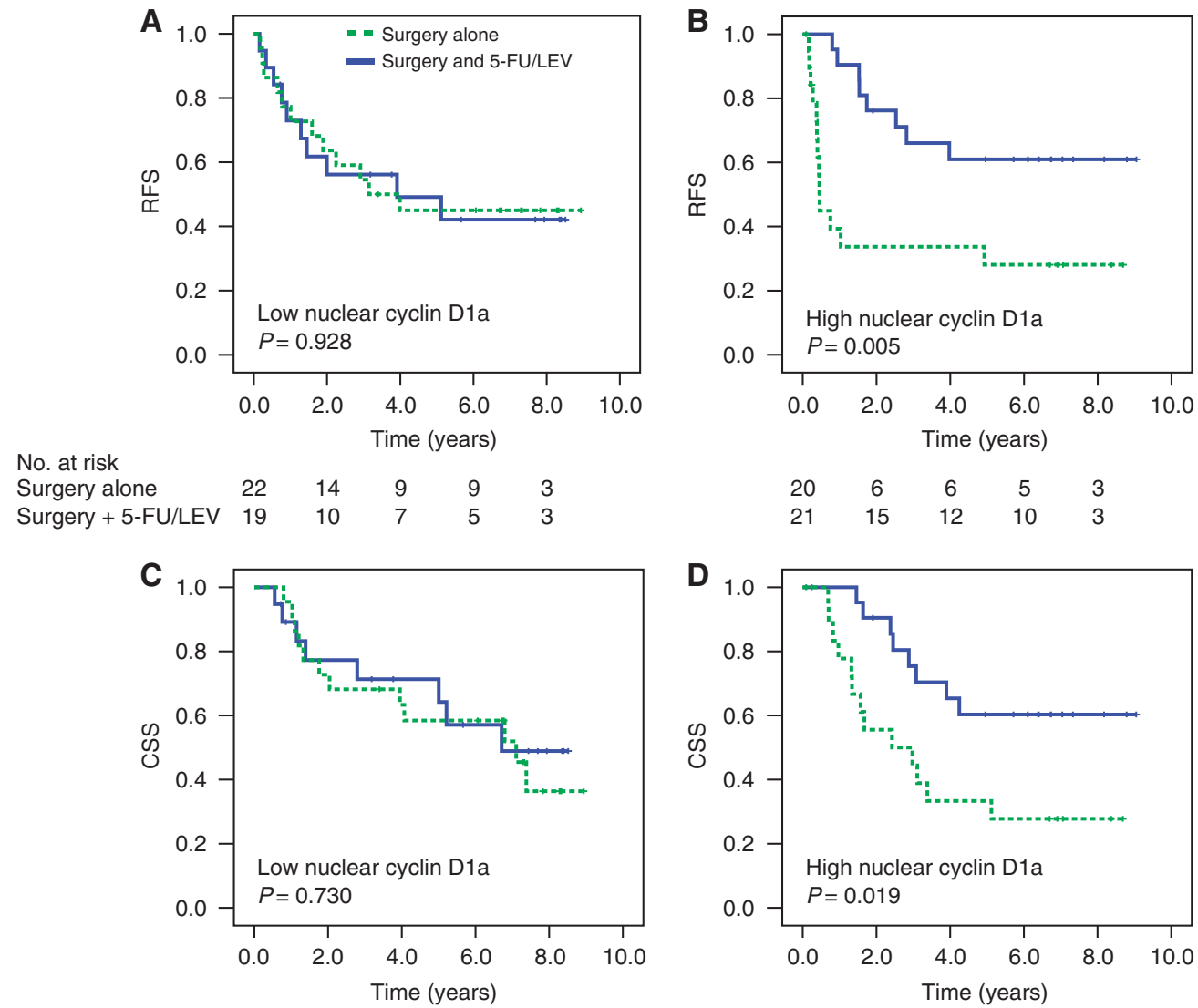

No. at risk

$\begin{array}{llllll}\text { Surgery alone } & 22 & 16 & 13 & 12 & 3\end{array}$

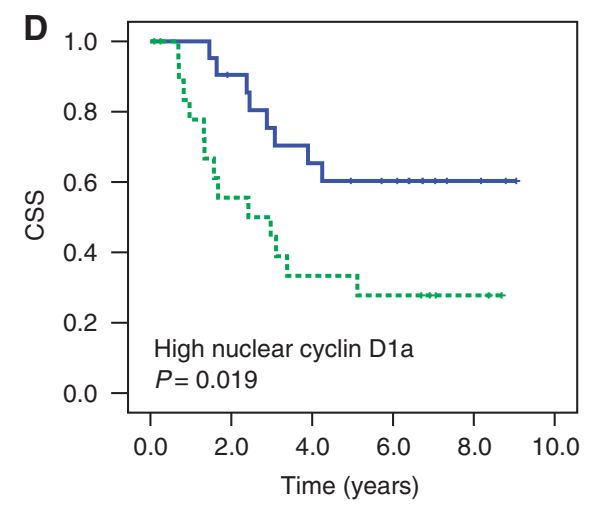

Surgery + 5-FU/LEV $19 \quad 13 \quad 10 \quad 7 \quad 3$

$\begin{array}{ccccc}20 & 10 & 6 & 5 & 2 \\ 21 & 18 & 13 & 10 & 3\end{array}$

Figure 3 Colon stage III patients and treatment response according to nuclear cyclin D I a expression. Curves are generated by the Kaplan-Meier method and $P$-values are from the log-rank test. Treatment response are measured in RFS ( $\mathbf{A}$ and $\mathbf{B})$ and CSS (C and $\mathbf{D})$ for low $(\mathbf{A}$ and $\mathbf{C})$ vs high (B and $\mathbf{D})$ expression of nuclear cyclin DIa. Green curves represent patients treated with surgery alone and blue patients treated with surgery plus adjuvant therapy (5FU/LEV). Abbreviations: CSS = cancer specific survival; RFS = relapse-free survival. 
showed a benefit of adjuvant treatment compared to the low cyclin D1a patients (Figure 3). The 5-year RFS for stage III patients with high cyclin D1a treated with adjuvant therapy $v s$ surgery alone was $61 \%$ and $28 \%$, respectively ( $P=0.005$, Figures $2 \mathrm{~A}$ and $\mathrm{B})$. A similar finding was noted for CSS in this 'high cyclin D1a' group; the CSS was $60 \%$ in the adjuvant group and $33 \%$ in the surgery alonetreated patients $(P=0.019)$. No significant association between cyclin D1a and other clinicopathological variables was demonstrated (Supplementary Table 1). Regarding cyclin D1b, no predictive value could be demonstrated for CRC or colon cancer patients (Supplementary Figure 1). However, we observed that the expected difference in survival between patients of stage III treated with surgery alone $v s$ adjuvant treatment was lost in patients with high expression of cyclin D1b (Figure 4).

Multivariate analyses including the colon cancer patients and the variables nuclear cyclin D1a, treatment group (adjuvant $v s$ surgery only), tumour localisation (distal vs proximal colon), tumour histological grade (poor $v s$ high/moderate) and stage (II $v s$ III) identified stage to be an independent predictor of RFS $(\mathrm{HR}=4.62,95 \% \mathrm{CI} 2.12-7.8, P<0.001)$ and CSS $(\mathrm{HR}=2.79,95 \%$ CI 1.41-5.53, $P=0.003$ ) (Table 2). Cyclin D1a status and treatment did not reach significance. When interaction was tested, it could be demonstrated for treatment group and nuclear cyclin D1a for both RFS and CSS $(P=0.004$ and $P=0.025$, respectively). No interaction between stage and cyclin D1a was noted for RFS $(P=0.092)$, but for CSS, this interaction was significant $(P=0.008)$. In stage III patients, no variables were found significant in multivariate analyses. No multivariate analyses were performed on stage II patients or rectal patients, because no variables were found significant in univariate analyses.

\section{DISCUSSION}

In the present study, we investigated the possible roles of the two cyclin D isoforms, cyclin D1a and D1b, as prognostic or predictive markers in CRC. Cyclin Dla was identified to be a predictive marker for benefit from adjuvant treatment with 5-FU/LEV in colon cancer both when we analysed stages II and III together and stage III alone. Patients with high expression of nuclear cyclin D1a in the tumour tissue showed a clear benefit from adjuvant 5-FU/ LEV treatment compared to surgery alone, measured in 5-year RFS and CSS. Patients with low cyclin D1a had no benefit from adjuvant treatment. The other isoform, cyclin D1b, was found to be neither a prognostic nor a predictive marker in CRC or in colon cancer. On the other hand, the expected benefit from adjuvant treatment was not found in the 'high' cyclin D1b group of colon cancer stage III. This may indicate that high expression of cyclin D1b has a negative effect on chemotherapy with 5-FU/LEV.

Cyclin D and cdk4/6 are important regulators of DNA replication and cell division (Sherr and Roberts, 2004; Besson et al, 2008). It is widely accepted that cyclin D is a key molecule in controlling the transition from phase $G_{1}$ of the cell cycle to $S$ phase through the mediation of $\mathrm{pRb}$. Consequently, deregulation of cyclin D1 will promote mitogen-independent proliferation, but may also affect angiogenesis (Hanai et al, 2002; Yasui et al, 2006),
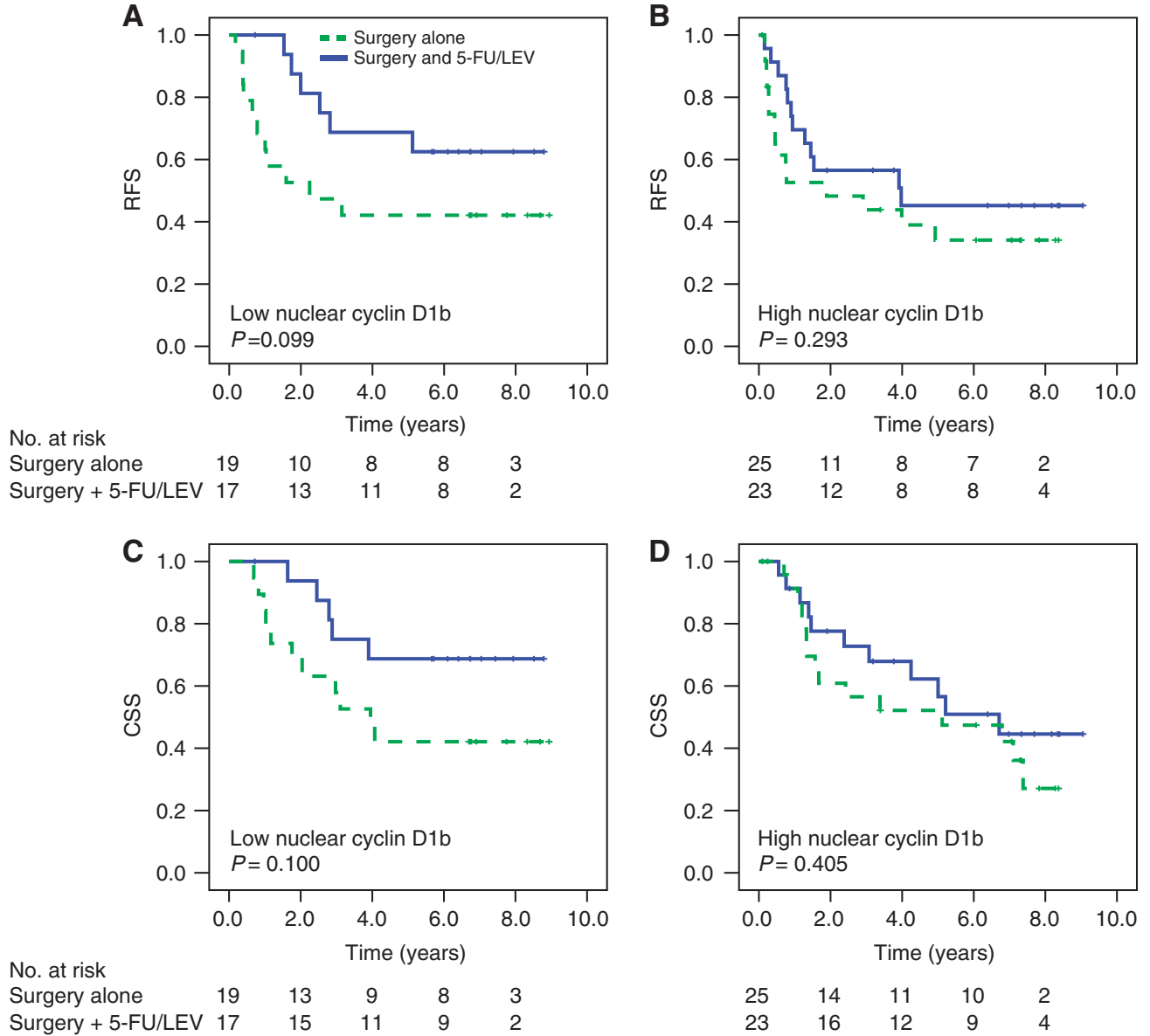

Figure 4 Colon cancer stage III patients and Kaplan-Meier estimates of RFS ( $\mathbf{A}$ and $\mathbf{B})$ and CSS (C and $\mathbf{D})$ after treatment with surgery alone vs surgery plus adjuvant chemotherapy (5-FU/LEV), according to nuclear cyclin D Ib expression. (A and D) Low cyclin D Ib. (B and C) High cyclin DIb. Abbreviations: CSS = cancer specific survival; RFS $=$ relapse-free survival. 
apoptosis (Albanese et al, 1999), mitochondrial metabolism (Wang et al, 2006), centrosome duplication (Nelsen et al, 2005) and DDR, with cyclin D1 interacting with proteins involved in DNA damage repair, including BRCA1 and Rad51 (Wang et al, 2005; Pontano et al, 2008; Li et al, 2010; Jirawatnotai et al, 2011). Recent research has shown that cyclin D1a and $\mathrm{b}$ isoforms regulate the DDR differently (Li et al, 2010). Overexpression of cyclin D1a was shown to enhance the DDR after double-strand breaks were caused by 5-FU treatment in cultured colon cancer cells. This study also presents evidence suggesting that the induction of DDR by cyclin Dla can be uncoupled from the induction of DNA synthesis. We hypothesised that the expression of nuclear cyclin D1a in tumour cells could predict the response to treatment with 5-FU given as adjuvant therapy in colorectal patients. According to the findings of Li et al, patients with high expression of cyclin D1a should benefit more from 5-FU treatment, compared to those with low expression of the marker. Our results confirm this hypothesis, but we do not exclude the possibility that the finding of high cyclin Dla as a predictor of positive response to 5-FU/LEV may be due to higher sensitivity to chemotherapy caused by the high proliferation rate in the responsive tumours. Former published work by our group showed that high expression of the proliferation marker Ki-67 predicted the effect of 5-FU/LEV in colon cancer (Fluge et al, 2009).

One advantage of the present study is that we were allowed to analyse surgery alone $v s$ adjuvant therapy as recommended in the search for prognostic factors (Hayes et al, 1998; Barratt et al, 2002). The treatment part of our study was planned and conducted at a time when surgery alone was the main treatment strategy for all CRC patients in Norway. Adjuvant treatment with 5-FU/LEV was considered an explorative treatment at that time. Today this would have been unethical as new and more effective treatment regimens have been introduced.

Cyclin D1 expression in colon and CRC has been studied by several research groups, but the reported findings are divergent (Maeda et al, 1997; McKay et al, 2000b, 2002; Mermelshtein et al, 2005; Kouraklis et al, 2006; Ioachim, 2008; Ogino et al, 2009;
Wangefjord et al, 2011). Some find cyclin D1 to have a prognostic value on colon or CRC, at least in univariate analysis, but others find no association between cyclin D1 protein expression and survival. The findings also diverge in whether low or high cyclin D1 is favourable. All these studies on cyclin D1 have used IHC, but the antibody used and the methods for scoring and interpreting differ. Other factors that differ among the studies are the number of patients included, and in several studies, no clear statement on treatment among the included patients is made, for example, surgery only, different adjuvant treatment regimes. This might, at least partially, explain the divergent results. To our knowledge, the present study is the first to investigate whether the cyclin D1 isoforms, D1a and $\mathrm{b}$, have different capabilities to predict prognosis or response to adjuvant therapy with 5-FU/LEV in CRC. Unfortunately, our cohort was not large enough to be divided into a training set and a validation set. The numbers in each survival group are small and may therefore give rise to somewhat uncertain analyses. Thus, further investigation is needed to confirm the clinical usefulness of this molecular marker.

In conclusion, the findings of the present study indicate that high expression of nuclear cyclin D1a predicts favourable response for adjuvant therapy with 5-FU. The results also implicate that high cyclin D1b may be a negative predictor for the effect of adjuvant treatment with 5-FU/LEV.

\section{ACKNOWLEDGEMENTS}

This project was funded by the Norwegian Cancer Society.

\section{Conflict of interest}

The authors declare no conflict of interest.

Supplementary Information accompanies the paper on British Journal of Cancer website (http://www.nature.com/bjc)

\section{REFERENCES}

Albanese C, D'Amico M, Reutens AT, Fu M, Watanabe G, Lee RJ, Kitsis RN, Henglein B, Avantaggiati M, Somasundaram K, Thimmapaya B, Pestell RG (1999) Activation of the cyclin D1 gene by the E1A-associated protein p300 through AP-1 inhibits cellular apoptosis. J Biol Chem 274(48): 34186-34195

Arber N, Doki Y, Han EK, Sgambato A, Zhou P, Kim NH, Delohery T, Klein MG, Holt PR, Weinstein IB (1997) Antisense to cyclin D1 inhibits the growth and tumorigenicity of human colon cancer cells. Cancer Res 57(8): 1569-1574

Arber N, Hibshoosh H, Moss SF, Sutter T, Zhang Y, Begg M, Wang S, Weinstein IB, Holt PR (1996) Increased expression of cyclin D1 is an early event in multistage colorectal carcinogenesis. Gastroenterology 110(3): 669-674

Bala S, Peltomaki P (2001) CYCLIN D1 as a genetic modifier in hereditary nonpolyposis colorectal cancer. Cancer Res 61(16): 6042-6045

Barratt PL, Seymour MT, Stenning SP, Georgiades I, Walker C, Birbeck K, Quirke P (2002) DNA markers predicting benefit from adjuvant fluorouracil in patients with colon cancer: a molecular study. Lancet 360(9343): 1381-1391

Besson A, Dowdy SF, Roberts JM (2008) CDK inhibitors: cell cycle regulators and beyond. Dev Cell 14(2): 159-169

Betticher DC, Thatcher N, Altermatt HJ, Hoban P, Ryder WD, Heighway J (1995) Alternate splicing produces a novel cyclin D1 transcript. Oncogene 11(5): 1005-1011

Cortessis VK, Siegmund K, Xue S, Ross RK, Yu MC (2003) A case-control study of cyclin D1 CCND1 $870 \mathrm{~A} \rightarrow \mathrm{G}$ polymorphism and bladder cancer. Carcinogenesis 24(10): 1645-1650
Dahl O, Fluge O, Carlsen E, Wiig JN, Myrvold HE, Vonen B, Podhorny N, Bjerkeset O, Eide TJ, Halvorsen TB, Tveit KM (2009) Final results of a randomised phase III study on adjuvant chemotherapy with $5 \mathrm{FU}$ and levamisol in colon and rectum cancer stage II and III by the Norwegian Gastrointestinal Cancer Group. Acta Oncol 48(3): 368-376

Derwinger K, Carlsson G, Gustavsson B (2007) Stage migration in colorectal cancer related to improved lymph node assessment. Eur J Surg Oncol 33(7): 849-853

Diehl JA (2002) Cycling to cancer with cyclin D1. Cancer Biol Ther 1(3): 226-231

Dolled-Filhart M, Ryden L, Cregger M, Jirstrom K, Harigopal M, Camp RL, Rimm DL (2006) Classification of breast cancer using genetic algorithms and tissue microarrays. Clin Cancer Res 12(21): 6459-6468

Edler D, Ohrling K, Hallstrom M, Karlberg M, Ragnhammar P (2007) The number of analyzed lymph nodes - a prognostic factor in colorectal cancer. Acta Oncol 46(7): 975-981

Ferlay J, Shin HR, Bray F, Forman D, Mathers C, Parkin DM (2010) GLOBOCAN 2008, Cancer Incidence and Mortality Worldwide: IARC CancerBase No. 10 [Internet]

Fluge O, Gravdal K, Carlsen E, Vonen B, Kjellevold K, Refsum S, Lilleng R, Eide TJ, Halvorsen TB, Tveit KM, Otte AP, Akslen LA, Dahl O (2009) Expression of EZH2 and Ki-67 in colorectal cancer and associations with treatment response and prognosis. Br J Cancer 101(8): 1282-1289

Fu M, Wang C, Li Z, Sakamaki T, Pestell RG (2004) Minireview: cyclin D1: normal and abnormal functions. Endocrinology 145(12): 5439-5447

Hanai J, Dhanabal M, Karumanchi SA, Albanese C, Waterman M, Chan B, Ramchandran R, Pestell R, Sukhatme VP (2002) Endostatin causes G1 
arrest of endothelial cells through inhibition of cyclin D1. J Biol Chem 277(19): 16464-16469

Hayes DF, Trock B, Harris AL (1998) Assessing the clinical impact of prognostic factors: when is 'statistically significant' clinically useful? Breast Cancer Res Treat 52(1-3): 305-319

Holley SL, Parkes G, Matthias C, Bockmuhl U, Jahnke V, Leder K, Strange RC, Fryer AA, Hoban PR (2001) Cyclin D1 polymorphism and expression in patients with squamous cell carcinoma of the head and neck. Am J Pathol 159(5): 1917-1924

Howe D, Lynas C (2001) The cyclin D1 alternative transcripts [a] and [b] are expressed in normal and malignant lymphocytes and their relative levels are influenced by the polymorphism at codon 241 . Haematologica 86(6): 563-569

Hulit J, Wang C, Li Z, Albanese C, Rao M, Di Vizio D, Shah S, Byers SW, Mahmood R, Augenlicht LH, Russell R, Pestell RG (2004) Cyclin D1 genetic heterozygosity regulates colonic epithelial cell differentiation and tumor number in ApcMin mice. Mol Cell Biol 24(17): 7598-7611

Inaba $\mathrm{T}$, Matsushime $\mathrm{H}$, Valentine $\mathrm{M}$, Roussel MF, Sherr CJ, Look AT (1992) Genomic organization, chromosomal localization, and independent expression of human cyclin D genes. Genomics 13(3): 565-574

Ioachim E (2008) Expression patterns of cyclins D1, E and cyclindependent kinase inhibitors p21waf1/cip1, p27kip1 in colorectal carcinoma: correlation with other cell cycle regulators (pRb, p53 and Ki-67 and PCNA) and clinicopathological features. Int I Clin Pract 62(11): 1736-1743

Jirawatnotai S, Hu Y, Michowski W, Elias JE, Becks L, Bienvenu F, Zagozdzon A, Goswami T, Wang YE, Clark AB, Kunkel TA, van Harn T, Xia B, Correll M, Quackenbush J, Livingston DM, Gygi SP, Sicinski P (2011) A function for cyclin D1 in DNA repair uncovered by protein interactome analyses in human cancers. Nature 474(7350): 230-234

Kong S, Wei Q, Amos CI, Lynch PM, Levin B, Zong J, Frazier ML (2001) Cyclin D1 polymorphism and increased risk of colorectal cancer at young age. J Natl Cancer Inst 93(14): 1106-1108

Kouraklis G, Theocharis S, Vamvakas P, Vagianos C, Glinavou A, Giaginis C, Sioka C (2006) Cyclin D1 and Rb protein expression and their correlation with prognosis in patients with colon cancer. World J Surg Oncol 4: 5

Le Marchand L, Seifried A, Lum-Jones A, Donlon T, Wilkens LR (2003) Association of the cyclin D1 A870G polymorphism with advanced colorectal cancer. JAMA 290(21): 2843-2848

Li Z, Jiao X, Wang C, Shirley LA, Elsaleh H, Dahl O, Wang M, Soutoglou E, Knudsen ES, Pestell RG (2010) Alternative cyclin D1 splice forms differentially regulate the DNA damage response. Cancer Res 70(21): $8802-8811$

Lu F, Gladden AB, Diehl JA (2003) An alternatively spliced cyclin D1 isoform, cyclin D1b, is a nuclear oncogene. Cancer Res 63(21): 7056-7061

Lukas J, Parry D, Aagaard L, Mann DJ, Bartkova J, Strauss M, Peters G, Bartek J (1995) Retinoblastoma-protein-dependent cell-cycle inhibition by the tumour suppressor p16. Nature 375(6531): 503-506

Maeda K, Chung YS, Kang SM, Ogawa M, Onoda N, Nakata B, Nishiguchi Y, Ikehara T, Okuno M, Sowa M (1997) Overexpression of cyclin D1 and p53 associated with disease recurrence in colorectal adenocarcinoma. Int J Cancer 74(3): 310-315

McKay JA, Douglas JJ, Ross VG, Curran S, Ahmed FY, Loane JF, Murray GI, McLeod HL (2000a) Expression of cell cycle control proteins in primary colorectal tumors does not always predict expression in lymph node metastases. Clin Cancer Res 6(3): 1113-1118

McKay JA, Douglas JJ, Ross VG, Curran S, Loane JF, Ahmed FY, Cassidy J, McLeod HL, Murray GI (2002) Analysis of key cell-cycle checkpoint proteins in colorectal tumours. J Pathol 196(4): 386-393

McKay JA, Douglas JJ, Ross VG, Curran S, Murray GI, Cassidy J, McLeod HL (2000b) Cyclin D1 protein expression and gene polymorphism in colorectal cancer. Aberdeen Colorectal Initiative. Int J Cancer 88(1): 77-81

Mercier I, Casimiro MC, Zhou J, Wang C, Plymire C, Bryant KG, Daumer KM, Sotgia F, Bonuccelli G, Witkiewicz AK, Lin J, Tran TH, Milliman J,
Frank PG, Jasmin JF, Rui H, Pestell RG, Lisanti MP (2009) Genetic ablation of caveolin-1 drives estrogen-hypersensitivity and the development of DCIS-like mammary lesions. Am J Pathol 174(4): 1172-1190

Mermelshtein A, Gerson A, Walfisch S, Delgado B, Shechter-Maor G, Delgado J, Fich A, Gheber L (2005) Expression of D-type cyclins in colon cancer and in cell lines from colon carcinomas. $\mathrm{Br} J$ Cancer 93(3): $338-345$

Nelsen CJ, Kuriyama R, Hirsch B, Negron VC, Lingle WL, Goggin MM, Stanley MW, Albrecht JH (2005) Short term cyclin D1 overexpression induces centrosome amplification, mitotic spindle abnormalities, and aneuploidy. J Biol Chem 280(1): 768-776

Ogino S, Nosho K, Irahara N, Kure S, Shima K, Baba Y, Toyoda S, Chen L, Giovannucci EL, Meyerhardt JA, Fuchs CS (2009) A cohort study of cyclin D1 expression and prognosis in 602 colon cancer cases. Clin Cancer Res 15(13): 4431-4438

Ohtsubo M, Theodoras AM, Schumacher J, Roberts JM, Pagano M (1995) Human cyclin E, a nuclear protein essential for the G1-to-S phase transition. Mol Cell Biol 15(5): 2612-2624

Pontano LL, Aggarwal P, Barbash O, Brown EJ, Bassing CH, Diehl JA (2008) Genotoxic stress-induced cyclin D1 phosphorylation and proteolysis are required for genomic stability. Mol Cell Biol 28(23): 7245-7258

Schernhammer ES, Tranah GJ, Giovannucci E, Chan AT, Ma J, Colditz GA, Hunter DJ, Willett WC, Fuchs CS (2006) Cyclin D1 A870G polymorphism and the risk of colorectal cancer and adenoma. Br J Cancer 94(6): 928-934

Sherr CJ (1995) D-type cyclins. Trends Biochem Sci 20(5): 187-190

Sherr CJ, Roberts JM (2004) Living with or without cyclins and cyclindependent kinases. Genes Dev 18(22): 2699-2711

Solomon DA, Wang Y, Fox SR, Lambeck TC, Giesting S, Lan Z, Senderowicz AM, Conti CJ, Knudsen ES (2003) Cyclin D1 splice variants. differential effects on localization, RB phosphorylation, and cellular transformation. J Biol Chem 278(32): 30339-30347

Vidal A, Koff A (2000) Cell-cycle inhibitors: three families united by a common cause. Gene 247(1-2): 1-15

Wang C, Fan S, Li Z, Fu M, Rao M, Ma Y, Lisanti MP, Albanese C, Katzenellenbogen BS, Kushner PJ, Weber B, Rosen EM, Pestell RG (2005) Cyclin D1 antagonizes BRCA1 repression of estrogen receptor alpha activity. Cancer Res 65(15): 6557-6567

Wang C, Li Z, Lu Y, Du R, Katiyar S, Yang J, Fu M, Leader JE, Quong A, Novikoff PM, Pestell RG (2006) Cyclin D1 repression of nuclear respiratory factor 1 integrates nuclear DNA synthesis and mitochondrial function. Proc Natl Acad Sci USA 103(31): 11567-11572

Wang L, Habuchi T, Mitsumori K, Li Z, Kamoto T, Kinoshita H, Tsuchiya N, Sato K, Ohyama C, Nakamura A, Ogawa O, Kato T (2003) Increased risk of prostate cancer associated with AA genotype of cyclin D1 gene A870G polymorphism. Int J Cancer 103(1): 116-120

Wang L, Habuchi T, Takahashi T, Mitsumori K, Kamoto T, Kakehi Y, Kakinuma H, Sato K, Nakamura A, Ogawa O, Kato T (2002) Cyclin D1 gene polymorphism is associated with an increased risk of urinary bladder cancer. Carcinogenesis 23(2): 257-264

Wang Y, Dean JL, Millar EK, Tran TH, McNeil CM, Burd CJ, Henshall SM, Utama FE, Witkiewicz A, Rui H, Sutherland RL, Knudsen KE, Knudsen ES (2008) Cyclin D1b is aberrantly regulated in response to therapeutic challenge and promotes resistance to estrogen antagonists. Cancer Res 68(14): 5628-5638

Wangefjord S, Manjer J, Gaber A, Nodin B, Eberhard J, Jirstrom K (2011) Cyclin D1 expression in colorectal cancer is a favorable prognostic factor in men but not in women in a prospective, population-based cohort study. Biol Sex Differ 2: 10

Yasui M, Yamamoto H, Ngan CY, Damdinsuren B, Sugita Y, Fukunaga H, Gu J, Maeda M, Takemasa I, Ikeda M, Fujio Y, Sekimoto M, Matsuura N, Weinstein IB, Monden M (2006) Antisense to cyclin D1 inhibits vascular endothelial growth factor-stimulated growth of vascular endothelial cells: implication of tumour vascularization. Clin Cancer Res 12(15): 4720-4729

This work is published under the standard license to publish agreement. After 12 months the work will become freely available and the license terms will switch to a Creative Commons Attribution-NonCommercial-Share Alike 3.0 Unported License. 